\title{
Optical imaging of artificial latent fingerprints using Rhodamine 6G and Au-core/Pd-shell nanorods
}

\author{
Kitsakorn Locharoenrat and Pattareeya Damrongsak
}

Biomedical Physics Research Unit, Department of Physics, Faculty of Science, King Mongkut's Institute of Technology Ladkrabang, Bangkok 10520, Thailand, kitsakorn.lo@kmitl.ac.th

Received: 15.05 .2019

\begin{abstract}
Latent fingerprints represent valuable information-storage platforms, which play a key role in the forensic practice and health assessment. Recent works have explored novel image-enhancement methods in latent fingerprinting, which are associated with fluorescence dyes. In this study we improve the quality of fingerprint images, using a combination of fluorescence dyes and bimetallic nanoparticles. We find that Rhodamine $6 \mathrm{G}$ can serve as a kind of 'glue' adhering well onto $\mathrm{Au}-\mathrm{Pd}$ core-shell nanorods. This system which employs molecules like $\alpha$ amylase can be successfully used for recognition of artificial latent fingerprints. The appropriate mechanism can be coupling of localized surface plasmon resonance in the nanorods mentioned above and the emission of Rhodamine $6 \mathrm{G}$. As a result, we observe notable enhancement of the images of artificial latent fingerprints.
\end{abstract}

Keywords: latent fingerprints, image contrast, fluorescence dyes, nanoparticles

UDC: 535.243 .2

\section{Introduction}

Latent fingerprints are based on specific compounds with latent-print residues transferred onto a substrate, which lead to the impression of ridge pattern left afterwards [1]. It mainly originates from a mixture of substances such as eccrine and sebaceous glands in the dermis, intrinsic components (metabolites, medication traces, drug usages, etc.) and extrinsic contaminants (e.g., blood, dirt, grease, make-up, food contaminants, moisturizers and hair-care products).

Eccrine sweat consists of proteins (e.g., albumin, histone and protamine) and carbohydrates (e.g., glucose, lactose and amylose). Sebaceous sweat contains lipids (i.e., fatty acids, fatty acid esters and glycerides), sterols (e.g., cholesterol and lipid esters) and squalene. Latent-fingerprint constituents of these particularly complex and variable matrices are subject to depositing and aging. Deposition stage is affected by donor factors (e.g., sex and race), transfer conditions such as contact time, angle and pressure, and the characteristics of substrates such as porosity, curvature and surface texture. Aging stage is influenced by substrate, environmental variations (e.g., temperature, humidity and light exposure), enhancement methods (e.g., optical, other physical and/or chemical), and time elapsed since the deposition stage. Knowledge of latent-fingerprint composition allows us to increase the awareness of reaction mechanisms occurring between enhancement-producing reagents and their target compounds. Moreover, it is important to develop current reagents and improve enhancement techniques to increase the resulting efficiency for both fresh and aged latent fingerprints. Any successful method for enhancing the latent fingerprints would have many potential benefits for both the forensic and biomedical sciences.

Many attempts have earlier been focused on the physical or chemical changes in the latent fingerprints, as well as their effects on subsequent image enhancement, using electromagnetic 
radiation, dyes or small-particle reagents. In particular, Merkel et al. have used a white light to generate topographic images of fingermarks on various substrates [2]. Nakamura et al. have revealed advantages of green lasers over blue or yellow ones in visualizing untreated fingermarks on steel and plaster walls [3]. Bond has advocated ultraviolet light in indentifying the fingermarks on thermal papers [4]. Rohatgi et al. have applied the small-particle reagents based on a fuchsin dye to develop the fingermarks on nonporous surfaces [5]. Dhall et al. have recommended the small-particle reagents based on zinc carbonate and eosin dye for the same aim [6]. To identify the fingermarks on colour nonporous surfaces, Sodhi et al. have used small-particle reagents based on zinc carbonate and crystal violet [7]. Braasch et al. have applied Nile red for developing the fingermarks on wet papers [8]. Ninhydrin can be used in order to enhance the blood-contaminated fingerprints on colour porous papers [9]. Nile blue can also be employed when observing the fingermarks on various papers [10]. In case of the fingermarks on moist porous surfaces, Oil red-o is of some value [11]. To see better the enhanced ridge details of fingermarks on wet papers, Perry et al. have used curcumin [12]. Finally, Zampa et al. have explored on how well Fast blue-b develops cannabis-contaminated fingerprints on both nonporous and porous surfaces [13].

The studies mentioned above have mostly dealt with the fingerprint-image enhancement based on the fluorescent dyes. The latter images are often a subject to change over time, because it is highly possible to see a red shift in the fluorescence wavelengths from the fingerprints during a prolonged period of time. Fresh fingerprints can exhibit either green or yellow fluorescence, as compared to orange one for old fingerprints, for instance. Depending on the intensity of fluorescence from a single fluorescent dye, it is unlikely to provide a high-contrast mode for the fingerprint images. Therefore a combination of fluorescent and some other materials is expected to be used as a feature of more reliable methods. One of the possible advantages of such methods is examining the fluorescence produced by some compounds, and their consequent degradation via oxidation at a known wavelength [14].

Hence, more analysis is needed to find out the fluorescence methods based upon a degree of red shift for the fluorescence dyes. Our idea is to study incorporation of fluorescence dyes into a system of noble-metal bimetallic nanoparticles. The underlying reason for this is discretization of the band-gap structure of nanoparticles, which can reveal fluorescence under excitation by specific light sources. In the present work we report on preparation of a combination of Rhodamine $6 \mathrm{G}$ (Rh6G) with Au-Pd core-shell nanorods (CSNRs) for its further use in artificial latent fingerprinting. We have found that, if compared to the common case of white-light illumination, the fingerprint images are notably enhanced in this system due to absorption of green-LED light.

\section{Experimental}

In order to create the artificial latent fingerprints, a freely downloaded cartoon fingerprint model was transferred on a transparent card via a copy machine. After that, gelatine solution (Sigma Aldrich, USA) serving as an artificial fingerprint was deposited on a substrate. It was left under ambient temperature for $24 \mathrm{~h}$. $\alpha$-amylase (Sigma Aldrich, USA), which served as a latent-print residue, was then dropped on the artificial fingerprints. Finally, the fingerprints were put in a fridge to dry them. The artificial latent fingerprints thus prepared were ready for our subsequent studies.

We prepared Rh6G (Sigma Aldrich, USA) with the constant concentration $1.5 \mu \mathrm{M}$ from a $6.0 \mu \mathrm{M}$ stock solution. Concentrations of Au-Pd CSNRs (Nanoseedz, Hong Kong) were varied according to the ratios of Au-Pd CSNRs and Rh6G shown in Table 1. Note that the Au-Pd CSNRs

Ukr. J. Phys. Opt. 2019, Volume 20, Issue 3 
had the diameters $40 \pm 3 \mathrm{~nm}$ and the lengths $96 \pm 6 \mathrm{~nm}$. The sample solutions were divided into two sets. The first one was filled into a cuvette to check the fluorescence intensity as a function of mixture concentration, using a luminescence spectrometer (AvaSpec-EDU from Avantes, USA). The second set of prepared solutions was reacted on the artificial latent fingerprints after transferring them on an optical plastic type $(18 \mathrm{~mm}$ in width and $100 \mathrm{~mm}$ in length; Scotch $3 \mathrm{M} \# 600$, Thailand) under the force $10 \mathrm{~N}$ for $20 \mathrm{~s}$.

Table 1. Characteristics of mixed dye solutions prepared for artificial latent fingerprints. The molar concentration of Rh6G is fixed at $1.50 \mu \mathrm{M}$ (with $\mathrm{M}$ being measured in the units mole/l).

\begin{tabular}{ccc}
\hline $\begin{array}{l}\text { Sample } \\
\text { solution \# }\end{array}$ & $\begin{array}{l}\text { Molar concentration } \\
\text { of Au-Pd CSNRs, mM }\end{array}$ & $\begin{array}{c}\text { Molar ratio of } \\
\text { Au-Pd CSNR : Rh6G }\end{array}$ \\
\hline 1 & 0.004 & $3: 1$ \\
2 & 0.009 & $6: 1$ \\
3 & 0.014 & $9: 1$ \\
4 & 0.018 & $13: 1$ \\
5 & 0.023 & $16: 1$ \\
6 & 0.070 & $47: 1$ \\
7 & 0.117 & $78: 1$ \\
8 & 0.164 & $110: 1$ \\
\hline
\end{tabular}

Microstructure of the latent fingerprints was investigated by an optical microscope (typical magnification 4×; Eclipse-E200 from Nikon, Japan). To observe and compare the quality of images of the enhanced fingerprints, the luminescence images from the fluorescence dye which coated the latent fingerprints were observed, using a LED-lamp illumination attachment to the microscope. Large oblique angles (60 deg) were used to highlight light scattering from the fingermarks though avoiding directly reflected light from them. A green-band excitation at the central wavelength $500 \mathrm{~nm}$ was used for the luminescence.

All the optical images were recorded with a CCD camera under both white-light and LED excitations. Note that our approach does not consider the existence of contaminants, although the latter are usually present in the latent fingerprints and could influence the appropriate fluorescence.

\section{Results and discussion}

After the fluorescence spectra have been obtained as functions of concentration of the mixed sample solutions (see Table 1), we calculate the fluorescence intensity ratio (i.e., the fluorescence intensity of the sample divided by that referred to a blank sample excited by the LED light). The results are shown in Fig. 1. The fluorescence is enhanced for the sample solutions \#\#1-4, whereas fluorescence quenching is evident for the sample solutions \#\#4-8. Since the fluorescence of a mixed sample solution can be either quenched or enhanced, a dual-mode imaging for simultaneous visualization of the artificial latent fingerprints is implemented in Fig. 2.

As a result of the above experiments, we have found that the plain fingerprint marks obtained using the untreated fluorescence dye are only slightly visible with the naked eye (not shown in figures). On the other hand, the imbedded fluorescence dye reveals the fingerprint marks which are much more remarkably visible with the unaided eye. For a comparison, we demonstrate the fingerprints observed using the deposited fluorescence dye with the white and LED light incident obliquely on the surfaces. Here the oblique incidence ensures identical conditions of the light and camera gain for the both sides of the fingerprint marks. Fig. 2a, b and Fig. 2c, d display the results for the artificial latent fingerprints, which we have obtained with fluorescence enhancement and quenching. In the both cases they are viewed under the incident white-light and LED 


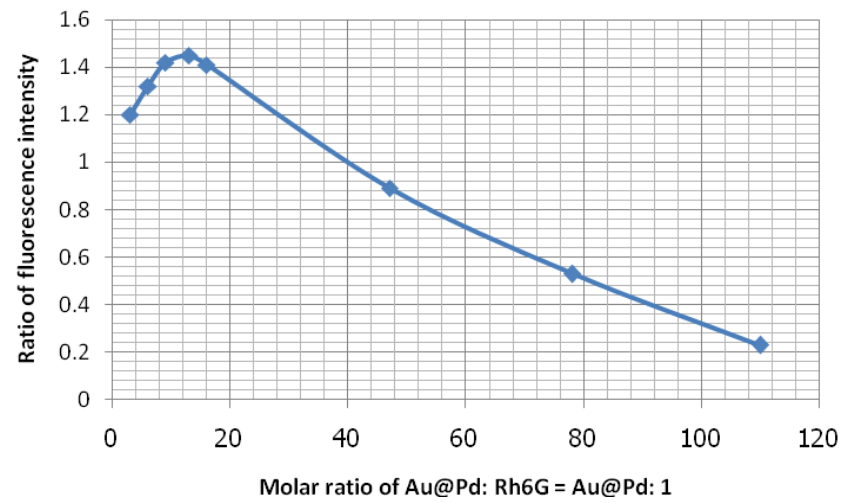

Fig. 1. Dependences of fluorescence intensity ratio on the concentration of solutions (see Table 1).

illuminations. The latent fingerprint marks are clearly visible in case of the fluorescence enhancement. The lines appearing because of fluorescence-dye deposition are clearly visible and continuous. Furthermore, the contrast agents like $\alpha$-amylase manifest the optical properties different from those of the background compounds. In other words, formation of clear black dots is observed in the bright field, whereas obvious green emission dots are seen in the dark field.

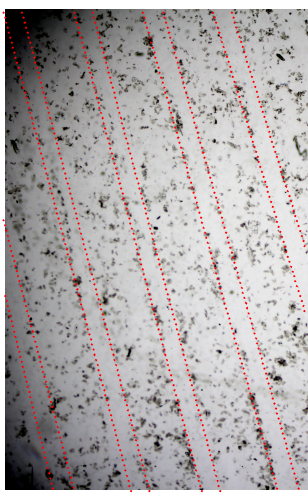

(a)

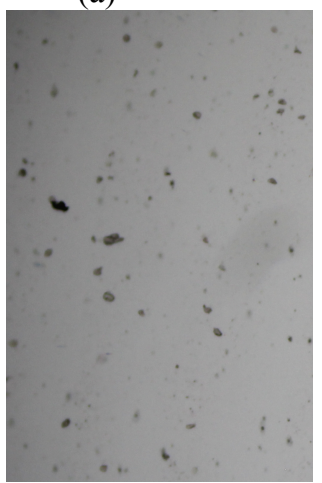

(c)

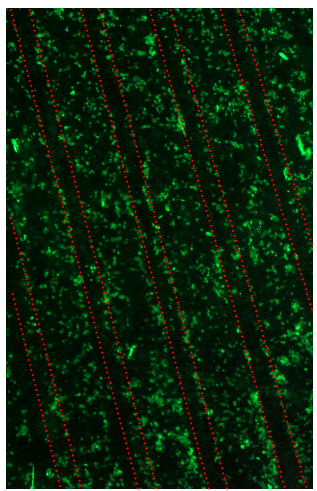

(b)

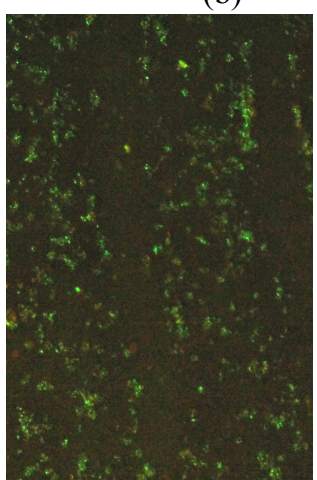

(d)

Fig. 2. Fluorescence images of developed artificial latent fingerprints, as obtained using representative sample solutions \#3 (top) and \#8 (bottom). Excitation sources are a white-light lamp (a, c) and a LED (b, d). The photoluminescence exists as at panels $(a, c)$ as well as at panels $(b, d)$.

In any case, the latent fingerprints marked by the fluorescence quenching are clearly visible and the lines due to the deposited dye become worse. It is hard to distinguish a difference between the obscure black dots observed in the bright field and the ambiguous green dots seen in the dark field. 
Note that the finger debris alone can be traced out and there is almost no continuity in the lines formed by the debris alone. To solve these problems, we have undertaken an optical-image contrast method using a program ImageJ (see Fig. 3). The aim is to confirm whether all the image details obtained with our fluorescence method (see Fig. 2) are seen well or not. Note that the image contrast is calculated using the following stages: (i) image pre-processing (i.e., background subtraction and noise reduction), (ii) image detection (i.e., detection of thresholds and regions of interests), and (iii) image measurement (i.e., quantifying intensity values and counting the gray value as a function of particular distance in the sample selected, where the image contrast is equal to a maximal gray value minus the minimum gray value). As a particular result, we have obtained the gray value in the region of $0-100$ and the sample distance of $0-1400$ pixels for the representative sample solution \#3 (see Fig. 3).

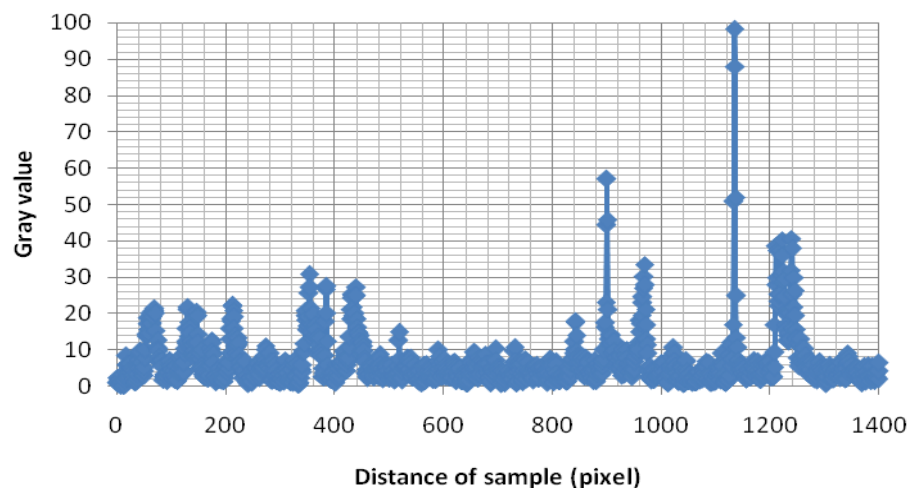

Fig. 3. Gray value as a function of sample distance obtained for the case of photoluminescence excited by LED light in the developed artificial latent fingerprints associated with representative sample solution \#3.

Further on, we have divided the image contrasts for the developed artificial latent fingerprints into two sets: one is for the case of fluorescence enhancement and another for the fluorescence quenching (see Fig. 4). One can notice that enhancement in the image contrast for the treated artificial latent fingerprints is extremely distinct in terms of the difference in the gray values for the ridge and valley patterns of the fingerprints. To be more specific, due to very high quantum efficiency of the luminescence, the fingerprint marks under the LED are much improved if compared with those obtained under the white light. For example, the image contrast obtained in the bright field due to fluorescence enhancement by the sample solutions \#\#1-3 (see Fig. 4a) is remarkably reduced, as compared to the luminescence images in the dark field obtained under the

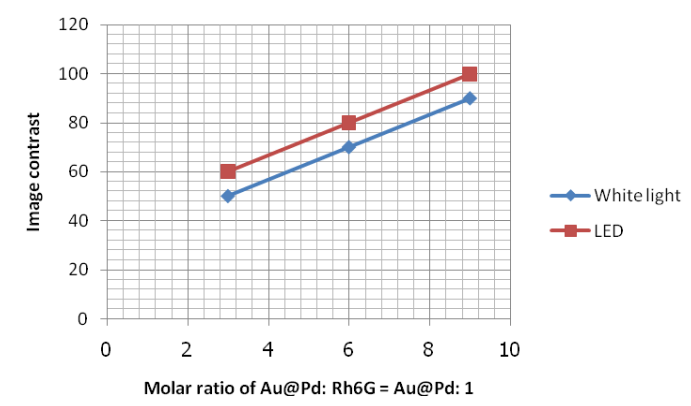

(a)

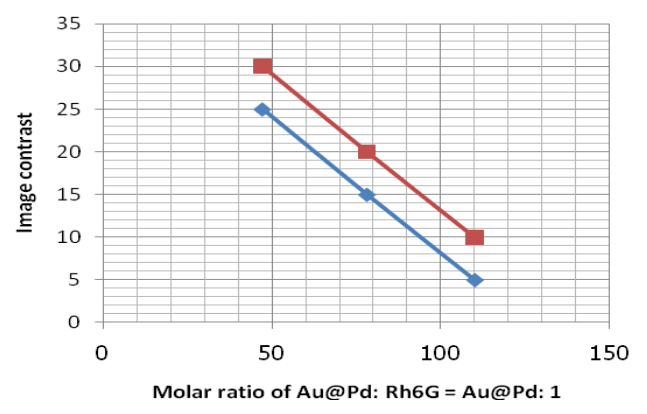

(b)

Fig. 4. Dependence of image contrast on the molar ratio for the cases of photoluminescence excited by white light and LED in the developed artificial latent fingerprints associated with representative sample solutions \#\#13 (a) and \#\#6-8 (b). 
$500 \mathrm{~nm}$ green-LED irradiation. On the other hand, the fingerprint information is still remarkably reduced, as compared to the luminescence images in the dark field obtained under the $500 \mathrm{~nm}$ green-LED irradiation. On the other hand, the fingerprint information is still readily obtained from the image contrast in the case of fluorescence quenching. For instance, the image contrast obtained in the bright field due to fluorescence quenching by the sample solutions \#\#6-8 is poorer (see Fig. 4b), if compared to that obtained in the luminescence images in the dark field under the $500 \mathrm{~nm}$ green-LED illumination.

Interestingly enough, the contrast of the photoluminesence images obtained for the treated latent fingerprints due to fluorescence enhancement is approximately four times higher than that obtained due to fluorescence quenching. The levels of the image contrast are determined by the following factors. First, they depend on how successfully hydrochromic mapping of the fluorescence dye and the Au-Pd CSNR is achieved. Second, the larger the surface area that the $\mathrm{Au}-\mathrm{Pd}$ CSNRs offer, the larger is the quantity of binding sites for the functional molecules like $\alpha$ amylase, quite similar to the human saliva for recognizing the targets within latent fingerprints. Finally, when localized surface plasmon resonance in Au-Pd CSNRs is simultaneously coupled with the emission of Rh6G by a single-excitation mode, the electromagnetic enhancement tends to facilitate the development of emission mode in the latent fingerprints $[15,16]$.

\section{Conclusion}

This work has been focused on the effect of excitation and emission of hybrid materials on the imaging of artificial latent fingerprints. For this aim we have used the Rh6G dye and the Au-Pd CSNRs. The quality of the images of ridge and valley details in the fingerprints, which have been taken using the white-light source and the green LED, has been improved in terms of both the image resolution and the image contrast. Here large surface area of the Au-Pd CSNRs has offered good binding affinity for the Rh6G dye, thus enhancing the quality of fluorescently tagged latent fingerprints. Coupling between the surface plasmon in the Au-Pd CSNRs and the molecule of Rh6G in the excited state leads to a strong output fluorescence intensity. Hence, these phenomena can be regarded as responsible for improving the luminescence response in the latent fingerprints.

\section{Acknowledgements}

This work has been funded by the King Mongkut's Institute of Technology Ladkrabang, Bangkok 10520, Thailand. The authors thank Ekkachai Rammarat, Kamonthip Putaen, Kittituspong Wichachang and Suwanan Wangchang for fruitful discussions.

\section{References}

1. Daluz H M. Fundamentals of fingerprint analysis. Florida: CRC Press (2014).

2. Merkel R, Gruhn S, Dittmann J, Vielhauer C and Brautigam A, 2012. On non-invasive 2D and 3D chromatic white light image sensors for age determination of latent fingerprint. Foren. Sci. Int. 222: 52-70.

3. Nakamura A, Okuda H, Nagaoka T, Akiba N, Kurosawa K, Kuroki K, Ichikawa F, Torao A and Sota T, 2015. Portable hyperspectral imager with continuous wave green laser for identification and detection of untreated latent fingerprint on walls. Foren. Sci. Int. 254: 100-105.

4. Bond J W, 2015. A noninvasive and speculative method of visualizing latent fingerprint deposited on thermal paper. J. Foren. Sci. 60: 1034-1039.

5. Rohatgi R. and Kapoor A K, 2016. Development of latent fingerprint on wet non-porous surfaces with SPR based on basic fuchsin dye. Egypt. J. Foren. Sci. 6: 179-184.

Ukr. J. Phys. Opt. 2019, Volume 20, Issue 3 
6. Dhall J K, Sodhi G S and Kapoor A K, 2013. A novel method for the development of latent fingerprint recovered from arson simulation. Egypt. J. Foren. Sci. 3: 99-103.

7. Sodhi G S and Kaur J, 2012. A novel fluorescent small particle reagent for detecting latent fingerprint on wet non-porous items. Egypt. J. Foren. Sci. 2: 45-47.

8. Braasch K, de la Hunty M, Deppe J, Spindler X, Cantu A A, Maynard P, Lennard C and Roux C, 2013. Nile red: alternative to physical developer for the detection of latent fingermarks on wet porous surfaces? Foren. Sci. Int. 230: 4-80.

9. Thomas P and Farrugia K, 2013. An investigation into the enhancement of fingermarks in blood on paper with genipin and lawsone. Sci. Just. 53: 315-320.

10. Frick A A, Busetti F, Cross A and Lewis S W, 2014. Aqueous nile blue: a simple, versatile and safe reagent for the detection of latent fingermarks. Chem. Commun. 50: 3341-3343.

11. Honig M and Yoak J, 2016. Oil red O: a comparative performance study. J. Foren. Ident. 66: 118-133.

12. Perry H and Sears V G, 2015. The use of natural yellow 3 (curcumin) for the chemical enhancement of latent friction ridge detail on naturally weathered materials. J. Foren. Ident. 65: $45-66$.

13. Zampa F, Furlan G, Bellizia M, Iuliano G and Ripani L, 2014. New forensic perspective for fast blue B: from cannabinoid reagent in toxicology to latent fingerprint developer in drug cases. J. Foren. Ident. 64: 523-535.

14. Van Dam A, Schwarz J C V, De Vos J, Siebes M, Sijen T, Van Leeuwen T G, Aalders M C and Lambrechts S A G, 2014. Oxidation monitoring by fluorescence spectroscopy reveals the age of fingermarks. Angew. Chem. Int. Ed. 53: 6272-6275.

15. Rammarat E, Kraithong S, Wanichacheva N, Swanglap P, Yindeesuk W, Damrongsak P and Locharoenrat K, 2018. Rhodamine 6G and Au-Pd core-shell nanorods: fluorescence enhancement for detection of mercury. Ukr. J. Phys. Opt. 19: 191-198.

16. Locharoenrat K. Optical properties of solids: an introductory textbook. Singapore: Pan Stanford (2016).

Kitsakorn Locharoenrat and Pattareeya Damrongsak. 2019. Optical imaging of artificial latent fingerprints using Rhodamine 6G and Au-core/Pd-shell nanorods. Ukr.J.Phys.Opt. 20: 106 - 112. doi: $10.3116 / 16091833 / 20 / 3 / 106 / 2019$

Анотація. Приховані відбитки пальців є иінною інформаційно-накопичувальною платформою, яка відіграє ключову роль у судовій практиці та оцінці стану здоров'я. У недавніх дослідниџьких прачях вивчалися нові способи покращення зображень прихованих відбитків пальиів, пов'язані з флуоресцентними барвниками. У иььому дослідженні ми покращуємо якість зображень відбитків пальців, використовуючи комбінацію флуоресцентного барвника $i$ біметалічних наночастинок. Виявлено, щчо Родамін 6G може служити своєрідним «клеєм», який добре прилипає до наностержнів з ядром із Аи та оболонкою із Pd. Цю систему, що використовуе молекули типу $\alpha$-амілази, можсна успішно використовувати для розпізнавання цтуучних прихованих відбитків. Відповідним механізмом може бути взаємодія локалізованого поверхневого плазмонного резонансу в згаданих вище наностержнях і випромінювання Родаміну 6G. Як наслідок, спостерігаємо помітне посилення зображень штучних прихованих відбитків пальц̧ів 